Vietnam Journal of Mechanics, VAST, Vol.39, No. 1 (2017), pp. 31 - 50

DOI:10.15625/0866-7136/7582

\title{
MODAL ANALYSIS OF FUNCTIONALLY GRADED TIMOSHENKO BEAM
}

\author{
Nguyen Ngoc Huyen ${ }^{1}$, Nguyen Tien Khiem ${ }^{2, *}$ \\ ${ }^{1}$ Thuy Loi University, Hanoi, Vietnam \\ ${ }^{2}$ Institute of Mechanics, VAST, Hanoi, Vietnam \\ *E-mail: ntkhiem@imech.vast.vn \\ Received Deccember 27, 2015
}

\begin{abstract}
Dynamic analysis of FGM Timoshenko beam is formulated in the frequency domain taking into account the actual position of neutral plane. The problem formulation enables to obtain explicit expressions for frequency equation, natural modes and frequency response of the beam subjected to external load. The representations are straightforward not only to modal analysis and modal testing of FGM Timoshenko beam with general end conditions but also to study coupling of axial and flexural vibration modes. Numerical study is carried out to investigate effect of true neutral axis position and material properties on the modal parameters.
\end{abstract}

Keywords: FGM, Timoshenko beam, modal analysis.

\section{INTRODUCTION}

The functionally graded material (FGM) that usually composes of metal and ceramic constituents has been proved to be an advanced composite compared to the layered ones. The fundamentals of manufacturing technology, modeling and analysis of that material were reviewed in $[1,2]$. Since the FGM is increasingly used nowadays in the practice of high-tech industries the dynamic behavior of FGM structures becomes a vital problem. Though the powerful methods such as finite element [3-5], dynamic stiffness [6] and spectral element [7] have been all developed for analysis of FGM structures, the analytical method shows to be most simply and accurately applied for beam-like FGM structures. Aydogdu and Taskin [8] have examined different high-order shear deformation theories by computing natural frequencies of simply supported functionally graded beam and shown that the classical beam theory gives higher results. Li [9] developed a theory of functionally graded Timoshenko beam based on the assumption that axial and flexural deformations are uncoupled and used to study flexural waves and free vibration of Timoshenko beam. Pradhan and Chakraverty [10] studied natural frequencies of both Euler-Bernoulli and Timoshenko functionally graded beams in dependence

(C) 2017 Vietnam Academy of Science and Technology 
on material power-law exponent using Rayleigh-Ritz method. Authors of Ref. [11] investigated effect of slenderness ratio $(L / h)$ and the material distribution index $(n)$ on natural frequencies of a functionally graded beam using the first-order shear deformation theory of beam. Wei et al. [12] and Aydin [13] studied free vibration of functionally graded beam with edge cracks and dynamic responses of FG beams to moving loads were obtained in $[14,15]$.

Note that most of the aforementioned theories developed for dynamic analysis of functionally graded beam are based on the assumption that neutral plane coincides with the mid-plane of beam. This is not true for functionally graded beam, especially, in the case of high gradient of elasticity. Recently, Eltaher et al. [16] have studied effect of exact position of neutral axis on natural frequencies of functionally graded Euler-Bernoulli beam and stated that the mid-plane theory of FGM beam leads natural frequencies to be overestimated. The authors of present paper have investigated material constants calculated for functionally graded Timoshenko beam based on the neutral-plane theory [17]. Objective of this study is to apply the neutral plane theory for modal analysis of functionally graded Timoshenko beam. Namely, the dynamic problem of functionally graded Timoshenko beam is first formulated in the frequency domain that would be then solved to obtain analytical expressions for natural modes and frequency response functions. The obtained analytical solutions enable not only to investigate the effect of true position of neutral axis on the natural frequencies and mode shapes but also to study coupling of axial and flexural vibration modes. The numerical analysis of frequency response functions shows that natural frequencies and mode shape of functionally graded Timoshenko beam could be surely measured by conventional modal testing technique.

\section{GOVERNING EQUATIONS}

Consider a beam of length $L$, cross-section area $A=b \times h$ made of FGM with the parameters

$$
\left\{\begin{array}{c}
E(z) \\
G(z) \\
\rho(z)
\end{array}\right\}=\left\{\begin{array}{c}
E_{b} \\
G_{b} \\
\rho_{b}
\end{array}\right\}+\left\{\begin{array}{c}
E_{t}-E_{b} \\
G_{t}-G_{b} \\
\rho_{t}-\rho_{b}
\end{array}\right\}\left(\frac{z}{h}+\frac{1}{2}\right)^{n}, \quad-h / 2 \leq z \leq h / 2,
$$

where $E, G$ and $\rho$ stand for elasticity, shear modulus and material density and indexes $t$ and $b$ denote the top and bottom materials; $z$ is ordinate of the point from the central axis at high $h / 2$. Assuming linear theory of deformation, the displacement fields in the cross-section at $x$ are

$$
u(x, z, t)=u_{0}(x, t)-\left(z-h_{0}\right) \theta(x, t), \quad w(x, z, t)=w_{0}(x, t),
$$

with $u_{0}(x, t), w_{0}(x, t)$ being the displacements of neutral axis that is located at the high $h_{0}$ from the central axis; $\theta$ is slope of the cross-section. Therefore, constituting equations get the form

$$
\varepsilon_{x}=\partial u_{0} / \partial x-\left(z-h_{0}\right) \partial \theta / \partial x, \quad \gamma_{x z}=\partial w_{0} / \partial x-\theta,
$$

and

$$
\sigma_{x}=E(z) \varepsilon_{x}, \quad \tau_{x z}=\psi G(z) \gamma_{x z} .
$$


Suppose that the beam is subject to distributed loads (axial $-p_{a}(x, t)$ and flexural $-p_{b}(x, t)$, the Hamilton principle allows the equations of motion in the time domain

$$
\begin{gathered}
\left(I_{11} \ddot{u}-A_{11} u^{\prime \prime}\right)-\left(I_{12} \ddot{\theta}-A_{12} \theta^{\prime \prime}\right)=p_{a}(x, t), \\
\left(I_{12} \ddot{u}-A_{12} u^{\prime \prime}\right)-\left(I_{22} \ddot{\theta}-A_{22} \theta^{\prime \prime}\right)+A_{33}\left(w^{\prime}-\theta\right)=0, \\
I_{11} \ddot{w}-A_{33}\left(w^{\prime \prime}-\theta^{\prime}\right)=p_{b}(x, t),
\end{gathered}
$$

where

$$
\begin{aligned}
\left(A_{11}, A_{12}, A_{22}\right) & =\int_{A} E(z)\left(1, z-h_{0},\left(z-h_{0}\right)^{2}\right) d A, \quad A_{33}=\psi \int_{A} G(z) d A, \\
\left(I_{11}, I_{12}, I_{22}\right) & =\int_{A} \rho(z)\left(1, z-h_{0},\left(z-h_{0}\right)^{2}\right) d A .
\end{aligned}
$$

Note that using the power law (1) for FGM material the constants (6) can be calculated as

$$
\begin{aligned}
& A_{11}=b h E_{b} \frac{\left(R_{1}+n\right)}{(1+n)}, I_{11}=b h \rho_{b} \frac{\left(R_{2}+n\right)}{(1+n)}, A_{12}=b h^{2} E_{b}\left[\frac{2 R_{1}+n}{2(2+n)}-\frac{R_{1}+n}{(1+n)} \alpha\right], \alpha=1 / 2+h_{0} / h, \\
& I_{12}=b h^{2} \rho_{b}\left[\frac{2 R_{2}+n}{2(2+n)}-\frac{R_{2}+n}{(1+n)} \alpha\right], A_{22}=b h^{3} E_{b}\left[\frac{3 R_{1}+n}{3(3+n)}-\frac{2 R_{1}+n}{(2+n)} \alpha+\frac{R_{1}+n}{(1+n)} \alpha^{2}\right], R_{3}=\frac{G_{t}}{G_{b}}, \\
& I_{22}=b h^{3} \rho_{b}\left[\frac{3 R_{2}+n}{3(3+n)}-\frac{2 R_{2}+n}{(2+n)} \alpha+\frac{R_{2}+n}{(1+n)} \alpha^{2}\right], A_{33}=b h \psi G_{b} \frac{\left(R_{3}+n\right)}{(1+n)}, R_{1}=\frac{E_{t}}{E_{b}}, R_{2}=\frac{\rho_{t}}{\rho_{b}} .
\end{aligned}
$$

As the deviation of neutral plane from the central one is determined

$$
h_{0}=\frac{n\left(R_{1}-1\right) h}{2(n+2)\left(n+R_{1}\right)} \quad \text { or } \quad \bar{h}_{0}=h_{0} / h=\frac{n\left(R_{1}-1\right)}{2(n+2)\left(n+R_{1}\right)},
$$

the coefficient $A_{12}=0$ and

$$
I_{12}=\frac{b h^{2} \rho_{b}\left(R_{2}-R_{1}\right) n}{2(2+n)\left(R_{1}+n\right)} \quad \text { or } \quad \bar{I}_{12}=\frac{I_{12}}{b h^{2} \rho_{b}}=\frac{\left(R_{2}-R_{1}\right) n}{2(2+n)\left(R_{1}+n\right)} .
$$

It can be seen from Eq. (5) that the coefficient $A_{12}, I_{12}$ represent coupling of axial and flexural vibrations. Indeed, if $I_{12}=A_{12}=0$ the first equation in (5) is uncoupled with two other equations that means obviously uncoupling of the axial and flexural vibrations. Therefore, condition for uncoupling of axial and flexural vibrations is $R_{1}=R_{2}$ or $n=0$. In this uncoupling case the Eq. (7) yields

$$
\frac{A_{11}}{I_{11}}=\frac{A_{22}}{I_{22}}=\frac{E_{t}}{\rho_{t}}=\frac{E_{b}}{\rho_{b}}=R,
$$

and system of equations (5) is separated into the well known equations of uncoupled axial and flexural vibrations $[4,18]$

$$
\begin{gathered}
I_{11} \ddot{u}=A_{11} u^{\prime \prime}+p_{a}(x, t), \\
I_{22} \ddot{\theta}=A_{22} \theta^{\prime \prime}+A_{33}\left(w^{\prime}-\theta\right), \quad I_{11} \ddot{w}=A_{33}\left(w^{\prime \prime}-\theta^{\prime}\right)+p_{b}(x, t) .
\end{gathered}
$$

Shift of the neutral axis as function of elasticity ratio $\left(R_{1}\right)$ calculated by Eq. (8) for various values of power $n$ is shown in Fig. 1. From the graphs it can be observed that the 
neutral axis moves up if $R_{1}>1$ and down $R_{1}<1$. It is monotonically increasing with the elasticity ratio but the growing rate is first raises to a maximum at $n=\sqrt{2 R_{1}}$, then reduces with further growing $n$.

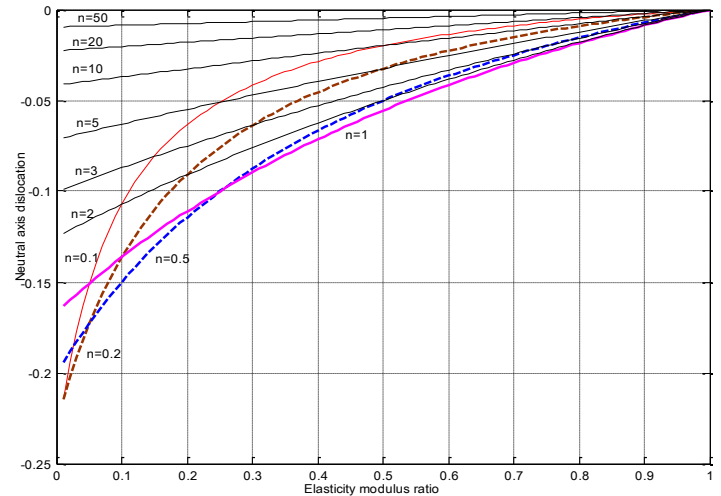

(a) $R_{1}<1$

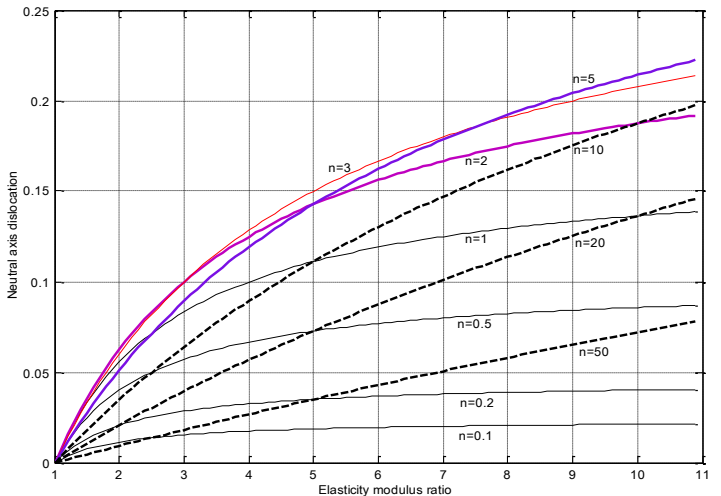

(b) $R_{1}>1$

Fig. 1. Neutral axis dislocation in dependence on the elasticity ratio and power $n$

As the coupling coefficient (9) is linearly dependent on the material density ratio $\left(R_{2}\right)$, there is given in Fig. 2 only the coefficient as function of elasticity modulus ratio for various values of $n$. It can be seen that the coupling coefficient is monotonically decreasing with growing elasticity ratio and rate of the decrease is strongly dependent on the power $n$, namely, in the case of $R_{1}>1$ the rate is increasing with $n$ and decreasing for $R_{1}<1$. Note that if neutral plane is assumed to be the mid-plane of beam then the coupling coefficient becomes constant (independent even on the index $n$ ) when $R_{2}=1$. So, involving the actual position of neutral plane not only leads the coefficient $A_{12}$ to

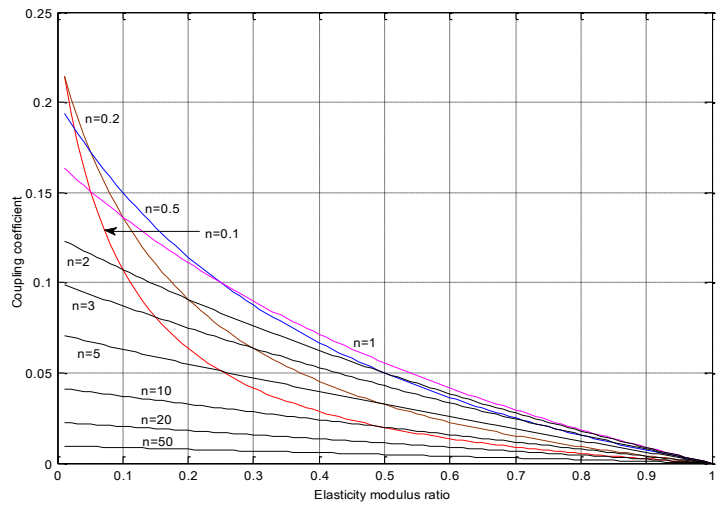

(a) $R_{2}=1, R_{1}<1$

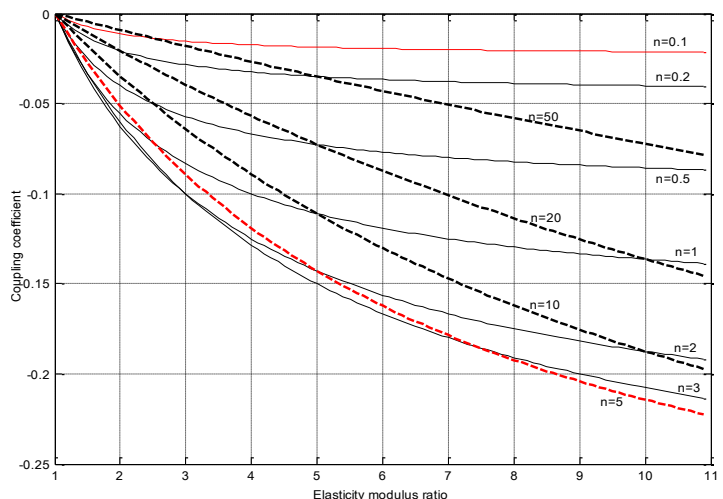

(b) $R_{2}=1, R_{1}>1$

Fig. 2. Coupling coefficient in dependence on the elasticity ratio and power $n$ 
vanish but also makes the mass and elasticity properties coupled through the coupling coefficient (9). Introducing the displacement amplitudes

$$
\begin{gathered}
\{U, \Theta, W\}=\int_{-\infty}^{\infty}\left\{u_{0}(x, t), \theta(x, t), w_{0}(x, t)\right\} e^{-i \omega t} d t \\
\left\{P_{a}(x, \omega), P_{m}(x, \omega), P_{b}(x, \omega)\right\}=\int_{-\infty}^{\infty}\left\{p_{a}(x, t), p_{m}(x, t), p_{b}(x, t)\right\} e^{-i \omega t} d t,
\end{gathered}
$$

Eqs. (5) become

$$
\begin{gathered}
\left(\omega^{2} I_{11} U+A_{11} U^{\prime \prime}\right)-\omega^{2} I_{12} \Theta=-P_{a}, \\
\left(\omega^{2} I_{22} \Theta+A_{22} \Theta^{\prime \prime}\right)-\omega^{2} I_{12} U+A_{33}\left(W^{\prime}-\Theta\right)=P_{m}, \\
\omega^{2} I_{11} W+A_{33}\left(W^{\prime \prime}-\Theta^{\prime}\right)=-P_{b} .
\end{gathered}
$$

Using the following matrix and vector notations

$$
\begin{gathered}
\mathbf{A}_{2}=\left[\begin{array}{ccc}
A_{11} & 0 & 0 \\
0 & A_{22} & 0 \\
0 & 0 & A_{33}
\end{array}\right], \mathbf{A}_{1}=\left[\begin{array}{ccc}
0 & 0 & 0 \\
0 & 0 & A_{33} \\
0 & -A_{33} & 0
\end{array}\right], \mathbf{A}_{0}=\left[\begin{array}{ccc}
\omega^{2} I_{11} & -\omega^{2} I_{12} & 0 \\
-\omega^{2} I_{12} & \omega^{2} I_{22}-A_{33} & 0 \\
0 & 0 & \omega^{2} I_{11}
\end{array}\right], \\
\mathbf{z}=\{U, \Theta, W\}^{T}, \quad \mathbf{q}=\left\{P_{a},-P_{m}, P_{b}\right\}^{T} .
\end{gathered}
$$

Eq. (15) are rewritten in form

$$
\mathbf{A}_{2} \mathbf{z}^{\prime \prime}+\mathbf{A}_{1} \mathbf{z}^{\prime}+\mathbf{A}_{0} \mathbf{z}+\mathbf{q}=0 .
$$

\section{FREE VIBRATION}

Eqs. (18) in the case of free vibration are

$$
\mathbf{A}_{2} \mathbf{z}^{\prime \prime}+\mathbf{A}_{1} \mathbf{z}^{\prime}+\mathbf{A}_{0} \mathbf{z}=0 .
$$

A continuous solution of Eq. (19) can be sought in the form $\mathbf{z}_{0}=\mathbf{d} e^{\lambda x}$ that yields the equation

$$
\left[\lambda^{2} \mathbf{A}_{2}+\lambda \mathbf{A}_{1}+\mathbf{A}_{0}\right] \mathbf{d}=0
$$

The latter equation would have nontrivial solution with respect to constant vector d under the condition

$$
\operatorname{det}\left[\lambda^{2} \mathbf{A}_{2}+\lambda \mathbf{A}_{1}+\mathbf{A}_{0}\right]=0
$$

that can be in turn expressed in the form

$$
\left.\left(\lambda^{2} A_{11}+\omega^{2} I_{11}\right)\left[\left(\lambda^{2} A_{33}+\omega^{2} I_{11}\right)\left(\lambda^{2} A_{22}+\omega^{2} I_{22}\right)-\omega^{2} I_{11} A_{33}\right)\right]-\left(\lambda^{2} A_{33}+\omega^{2} I_{11}\right) \omega^{4} I_{12}^{2}=0 .
$$

This is in fact a cubic algebraic equation with respect to $\eta=\lambda^{2}$

$$
\begin{gathered}
\eta^{3}+a \eta^{2}+b \eta+c=0, \\
a=\omega^{2}\left(I_{11} / A_{33}+I_{11} / A_{11}+I_{22} / A_{22}\right), \\
c=\omega^{4}\left[\left(\omega^{2} I_{11} / A_{33}\right)\left(I_{11} I_{22}-I_{12}^{2}\right) /\left(A_{11} A_{22}\right)-\left(I_{11}^{2} / A_{11} A_{22}\right)\right],
\end{gathered}
$$


$b=\omega^{4}\left[\left(I_{11} I_{22}-I_{12}^{2}\right) /\left(A_{11} A_{22}\right)+\left(I_{11} / A_{33}\right)\left(I_{11} / A_{11}+I_{22} / A_{22}\right)\right]-\omega^{2}\left(I_{11} / A_{22}\right)$,

that can be elementarily solved and gives three roots $\eta_{1}, \eta_{2}, \eta_{3}$. Therefore, roots of Eq. (21) are

$$
\lambda_{1,4}= \pm k_{1}, \quad \lambda_{2,5}= \pm k_{2}, \quad \lambda_{3,6}= \pm k_{3}, \quad k_{j}=\sqrt{\eta_{j}}, \quad j=1,2,3 .
$$

Now, general continuous solution of Eq. (19) can be represented as

$$
\mathbf{z}_{0}(x, \omega)=\sum_{j=1}^{6} \mathbf{d}_{j} e^{\lambda_{j} x}
$$

or in the matrix form

$$
\mathbf{z}_{0}=\left[\begin{array}{llll}
d_{11} & d_{12} & \ldots & d_{16} \\
d_{21} & d_{22} & \ldots & d_{26} \\
d_{31} & d_{32} & \ldots & d_{36}
\end{array}\right] \cdot\left\{\begin{array}{c}
e^{\lambda_{1} x} \\
\vdots \\
e^{\lambda_{6} x}
\end{array}\right\}
$$

Taking into account the first and last equations in (20) one gets

$$
\left[\begin{array}{llll}
d_{11} & d_{12} & \ldots & d_{16} \\
d_{21} & d_{22} & \ldots & d_{26} \\
d_{31} & d_{32} & \ldots & d_{36}
\end{array}\right]=\left[\begin{array}{cccc}
\alpha_{1} d_{21} & \alpha_{2} d_{22} & \ldots & \alpha_{6} d_{26} \\
d_{21} & d_{22} & \ldots & d_{26} \\
\beta_{1} d_{21} & \beta_{2} d_{22} & \ldots & \beta_{6} d_{26}
\end{array}\right]
$$

where

$$
\alpha_{j}=\omega^{2} I_{12} /\left(\omega^{2} I_{11}+\lambda_{j}^{2} A_{11}\right), \quad \beta_{j}=\lambda_{j} A_{33} /\left(\omega^{2} I_{11}+\lambda_{j}^{2} A_{33}\right), \quad j=1,2, \ldots, 6 .
$$

Using the notations introduced in (22) it is easily to verify that

$$
\alpha_{4}=\alpha_{1} ; \alpha_{5}=\alpha_{2} ; \alpha_{6}=\alpha_{3} ; \beta_{4}=-\beta_{1} ; \beta_{5}=-\beta_{2} ; \beta_{6}=-\beta_{3} .
$$

Hence, expression (23) can be now rewritten in the form

$$
\mathbf{z}_{0}(x, \omega)=\mathbf{G}(x, \omega) \mathbf{C},
$$

with $\mathbf{C}=\left(C_{1}, \ldots, C_{6}\right)^{T}=\left(d_{21}, \ldots, d_{26}\right)^{T}$ and

$$
\begin{gathered}
\mathbf{G}(x, \omega)=\left[\mathbf{G}_{1}(x, \omega) \mathbf{G}_{2}(x, \omega)\right], \\
\mathbf{G}_{1}(x, \omega)=\left[\begin{array}{ccc}
\alpha_{1} e^{k_{1} x} & \alpha_{2} e^{k_{2} x} & \alpha_{3} e^{k_{3} x} \\
e^{k_{1} x} & e^{k_{2} x} & e^{k_{3} x} \\
\beta_{1} e^{k_{1} x} & \beta_{2} e^{k_{2} x} & \beta_{3} e^{k_{3} x}
\end{array}\right], \mathbf{G}_{2}(x, \omega)=\left[\begin{array}{ccc}
\alpha_{1} e^{-k_{1} x} & \alpha_{2} e^{-k_{2} x} & \alpha_{3} e^{-k_{3} x} \\
e^{-k_{1} x} & e^{-k_{2} x} & e^{-k_{3} x} \\
-\beta_{1} e^{-k_{1} x} & -\beta_{2} e^{-k_{2} x} & -\beta_{3} e^{-k_{3} x}
\end{array}\right] .
\end{gathered}
$$

The solution (26) should fulfill conditions at the ends of the beam that can be represented in the form

$$
\left.\mathbf{B}_{0}\{\mathbf{z}\}\right|_{x=0}=0,\left.\quad \mathbf{B}_{L}\{\mathbf{z}\}\right|_{x=L}=0,
$$

where $\mathbf{B}_{0}, \mathbf{B}_{L}$ are differential operators of dimension $3 \times 3$. Decomposing the constant vector $\mathbf{C}=\left\{\mathbf{C}_{1}, \mathbf{C}_{2}\right\}^{T}$ with $\mathbf{C}_{1}=\left\{C_{1}, C_{2}, C_{3}\right\}^{T} ; \mathbf{C}_{2}=\left\{C_{4}, C_{5}, C_{6}\right\}^{T}$ the condition at the left end of beam can be expressed as

$$
\mathbf{B}_{01} \mathbf{C}_{1}+\mathbf{B}_{02} \mathbf{C}_{2}=0
$$


where

$$
\mathbf{B}_{01}(\omega)=\left.\mathbf{B}_{0}\left\{\mathbf{G}_{1}(x, \omega)\right\}\right|_{x=0}, \quad \mathbf{B}_{02}(\omega)=\left.\mathbf{B}_{0}\left\{\mathbf{G}_{2}(x, \omega)\right\}\right|_{x=0} .
$$

Obviously, Eq. (29) allows eliminating one of the vectors $\mathbf{C}_{1}, \mathbf{C}_{2}$ and as result one is able to reconstruct the solution $\mathbf{z}_{0}(x)$ as

$$
\mathbf{z}_{0}(x, \omega)=\mathbf{G}_{0}(x, \omega) \mathbf{D},
$$

with $\mathbf{G}_{0}(x, \omega)$ being $3 \times 3$ dimension matrix function (see Appendix) and arbitrary constant vector $\mathbf{D}=\left\{D_{1}, D_{2}, D_{3}\right\}^{T}$. Applying boundary conditions at the other end $(x=L)$ of beam for solution (30) one gets

$$
\begin{gathered}
{\left[\mathbf{B}_{L 0}(\omega)\right]\{\mathbf{D}\}=0,} \\
\mathbf{B}_{L 0}(\omega)=\left.\mathbf{B}_{L}\left\{\mathbf{G}_{0}(x, \omega)\right\}\right|_{x=L} .
\end{gathered}
$$

This equation has nontrivial solution only under the condition

$$
L_{0}(\omega)=\operatorname{det}\left[\mathbf{B}_{L 0}(\omega)\right]=0,
$$

that provides the so-called frequency equation for FGM beam. This equation can be rewritten in the explicit form

$$
\begin{gathered}
L_{0}(\omega) \equiv b_{11}(\omega)\left[b_{22}(\omega) b_{33}(\omega) b_{32}(\omega) b_{32}(\omega)\right]+b_{12}(\omega)\left[b_{31}(\omega) b_{23}(\omega)-b_{21}(\omega) b_{33}(\omega)\right]+ \\
+b_{23}(\omega)\left[b_{21}(\omega) b_{32}(\omega)-b_{31}(\omega) b_{22}(\omega)\right]=0
\end{gathered}
$$

with $b_{j k}(\omega), j, k=1,2,3$ being elements of the matrix $\mathbf{B}_{L 0}(\omega)$ defined by (32) and given in Appendix. Each root $\omega_{j}^{0}$ of the frequency equation is related to a mode shape

$$
\Phi_{j}^{0}(x)=C_{j}^{0} \mathbf{G}_{0}\left(x, \omega_{j}^{0}\right) \overline{\mathbf{D}}_{j},
$$

where $C_{j}^{0}$ is an arbitrary constant and $\overline{\mathbf{D}}_{j}$ is the normalized solution of (31) corresponding to $\omega_{j}^{0}$.

\section{FREQUENCY RESPONSE TO EXTERNAL LOAD}

This section is devoted to construct solution of Eq. (13) referred to as frequency response of FGM beam. As well known in the theory of differential equations general solution of the inhomogeneous equation is

$$
\mathbf{z}(x, \omega)=\mathbf{z}_{0}(x, \omega)-\mathbf{z}_{q}(x, \omega),
$$

with $\mathbf{z}_{q}(x, \omega)$ being a particular solution of inhomogeneous equation and $\mathbf{z}_{0}(x, \omega)$-general solution of homogeneous equation. General solution of homogeneous equation satisfying boundary conditions at the left end has been found in previous paragraph in the form of (30). The particular solution can be calculated by

$$
\mathbf{z}_{q}(x, \omega)=\int_{0}^{x} \mathbf{H}(x-\tau, \omega) \mathbf{q}(\tau, \omega) d \tau,
$$

where $\mathbf{H}(x, \omega)$ is so-called matrix of fundamental solutions conducted from the matrix equation

$$
\mathbf{A}_{2} \mathbf{H}^{\prime \prime}+\mathbf{A}_{1} \mathbf{H}^{\prime}+\mathbf{A}_{0} \mathbf{H}=0, \quad \mathbf{H}(0)=[0], \quad \mathbf{H}^{\prime}(0)=\mathbf{I}_{3} .
$$


Solution of latter equation can be obtained in the form

$$
\begin{gathered}
\mathbf{h}_{1}(x, \omega)=\left[\mathbf{H}_{1}(x, \omega)\right] \cdot\left\{\mathbf{a}_{1}\right\}, \quad \mathbf{h}_{2}(x, \omega)=\left[\mathbf{H}_{1}(x, \omega)\right] \cdot\left\{\mathbf{a}_{2}\right\}, \quad \mathbf{h}_{3}(x, \omega)=\left[\mathbf{H}_{3}(x)\right] \cdot\left\{\begin{array}{r}
\left.\mathbf{a}_{3}\right\}, \\
\mathbf{a}_{1}=\left\{a_{11}, a_{12}, a_{13}\right\}^{T}, \\
\mathbf{a}_{2}=\left\{a_{21}, a_{22}, a_{23}\right\}^{T}, \quad \mathbf{a}_{3}=\left\{a_{31}, a_{32}, a_{33}\right\}^{T},
\end{array}\right. \\
\mathbf{H}_{1}=\left[\begin{array}{ccc}
\alpha_{1} \sinh k_{1} x & \alpha_{2} \sinh k_{2} x & \alpha_{3} \sinh k_{3} x \\
\sinh k_{1} x & \sinh k_{2} x & \sinh k_{3} x \\
\beta_{1} \cosh k_{1} x & \beta_{2} \cosh k_{2} x & \beta_{3} \cosh k_{3} x
\end{array}\right], \mathbf{H}_{3}=\left[\begin{array}{ccc}
\alpha_{1} \cosh k_{1} x & \alpha_{2} \cosh k_{2} x & \alpha_{3} \cosh k_{3} x \\
\cosh k_{1} x & \cosh k_{2} x & \cosh k_{3} x \\
\beta_{1} \sinh k_{1} x & \beta_{2} \sinh k_{2} x & \beta_{3} \sinh k_{3} x
\end{array}\right]
\end{gathered}
$$

and

$$
\begin{gathered}
a_{11}=\left(k_{3} \beta_{2}-k_{2} \beta_{2}\right) / \Delta_{1}, \quad a_{12}=\left(k_{1} \beta_{3}-k_{3} \beta_{1}\right) / \Delta_{1}, \quad a_{13}=\left(k_{2} \beta_{1}-k_{1} \beta_{2}\right) / \Delta_{1}, \\
a_{21}=\left(\alpha_{2} k_{2} \beta_{3}-\alpha_{3} k_{3} \beta_{2}\right) / \Delta_{1}, \quad a_{22}=\left(\alpha_{3} k_{3} \beta_{1}-\alpha_{1} k_{1} \beta_{3}\right) / \Delta_{1}, a_{23}=\left(\alpha_{1} k_{1} \beta_{2}-\alpha_{2} k_{2} \beta_{1}\right) / \Delta_{1}, \\
a_{31}=\left(\alpha_{3}-\alpha_{2}\right) / \Delta_{2}, \quad a_{32}=\left(\alpha_{1}-\alpha_{3}\right) / \Delta_{2}, \quad a_{33}=\left(\alpha_{2}-\alpha_{1}\right) / \Delta_{2} ; \\
\Delta_{1}=\beta_{1} k_{2} k_{3}\left(\alpha_{3}-\alpha_{2}\right)+\beta_{2} k_{1} k_{3}\left(\alpha_{1}-\alpha_{3}\right)+\beta_{3} k_{1} k_{2}\left(\alpha_{2}-\alpha_{1}\right), \\
\Delta_{2}=\beta_{1} k_{1}\left(\alpha_{3}-\alpha_{2}\right)+\beta_{2} k_{2}\left(\alpha_{1}-\alpha_{3}\right)+\beta_{3} k_{3}\left(\alpha_{2}-\alpha_{1}\right) .
\end{gathered}
$$

Namely, the first and last vectors in (39) can be rewritten as

$$
\begin{aligned}
& \mathbf{h}_{1}(x, \omega)=\sum_{r=1}^{3} a_{1 r}\left\{\sinh k_{r} x ; \alpha_{r} \sinh k_{r} x, \beta_{r} \cosh k_{r} x\right\}^{T}, \\
& \mathbf{h}_{3}(x, \omega)=\sum_{r=1}^{3} a_{3 r}\left\{\cosh k_{r} x ; \alpha_{r} \cosh k_{r} x ; \beta_{r} \sinh k_{r} x\right\}^{T} .
\end{aligned}
$$

Obviously, such particular solution satisfies conditions $\mathbf{z}_{q}(0, \omega)=\mathbf{z}_{q}^{\prime}(0, \omega)=0$, so that solution (36) satisfying boundary conditions at the left end of beam can be expressed as

$$
\mathbf{z}(x)=\mathbf{G}_{0}(x, \omega) \mathbf{D}-\mathbf{z}_{q}(x, \omega) .
$$

Applying now boundary conditions at the right end for solution (45) leads to

$$
\left[\mathbf{B}_{L 0}(\omega)\right]\{\mathbf{D}\}=\left\{\mathbf{b}_{q}(\omega)\right\}
$$

where

$$
\mathbf{b}_{q}(\omega)=\left.\mathbf{B}_{L}\left\{\mathbf{z}_{q}(x, \omega)\right\}\right|_{x=L} .
$$

From the latter equations one gets

$$
\mathbf{D}=\left[\mathbf{B}_{L 0}(\omega)\right]^{-1}\left\{\mathbf{b}_{q}(\omega)\right\} .
$$

Thus, the frequency response of FGM beam to arbitrary load is finally obtained as

$$
\mathbf{z}(x, \omega)=\mathbf{G}_{0}(x, \omega)\left[\mathbf{B}_{L 0}(\omega)\right]^{-1}\left\{\mathbf{b}_{q}(\omega)\right\}-\mathbf{z}_{q}(x, \omega) .
$$

As an example, the frequency response of FGM beam subjected to an impulse force is derived below. In this case, assuming that

$$
p_{a}(x, t)=P_{a 0} \delta\left(x-x_{a}\right) \delta(t), \quad p_{m}(x, t)=0, \quad p_{b}(x, t)=P_{b 0} \delta\left(x-x_{b}\right) \delta(t),
$$

one has got $M=0$ and

$$
P_{a}(x, \omega)=P_{a 0} \delta\left(x-x_{a}\right), \quad P_{b}(x, \omega)=P_{b 0} \delta\left(x-x_{b}\right) .
$$


Therefore,

$$
\mathbf{z}_{q}\left(x, x_{a}, x_{b}, \omega\right)=P_{a 0} \mathbf{h}_{1}\left(x-x_{a}, \omega\right)+P_{b 0} \mathbf{h}_{3}\left(x-x_{b}, \omega\right),
$$

with vector-functions $\mathbf{h}_{k}(x), k=1,3$ given in (39). Putting (51) into (47) yields

$$
\begin{gathered}
\mathbf{b}_{q}(\omega)=\left.\mathbf{B}_{L}\left\{\mathbf{z}_{q}(x, \omega)\right\}\right|_{x=L}=P_{a 0}\left[\mathbf{B}_{L 1}(\omega)\right]\left\{\mathbf{a}_{1}\right\}+P_{b 0}\left[\mathbf{B}_{L 3}(\omega)\right]\left\{\mathbf{a}_{3}\right\}, \\
\mathbf{B}_{L 1}(\omega)=\mathbf{B}_{L}\left\{\left.\mathbf{H}_{1}\left(x-x_{a}, \omega\right\}\right|_{x=L}, \quad \mathbf{B}_{L 3}(\omega)=\mathbf{B}_{L}\left\{\left.\mathbf{H}_{3}\left(x-x_{b}, \omega\right\}\right|_{x=L} .\right.\right.
\end{gathered}
$$

Therefore,

$$
\mathbf{D}=\left[\mathbf{B}_{L 0}(\omega)\right]^{-1}\left\{P_{a 0}\left[\mathbf{B}_{L 1}(\omega)\right]\left\{\mathbf{a}_{1}\right\}+P_{b 0}\left[\mathbf{B}_{L 3}(\omega)\right]\left\{\mathbf{a}_{3}\right\}\right\},
$$

Thus, frequency response of the beam to impulse load (50) given by (45) would be completely determined

$$
\begin{array}{r}
\mathbf{h}(x, \omega)=P_{a 0}\left[\mathbf{H}_{a}\left(x, x_{a}, \omega\right)\right] \cdot\left\{\mathbf{a}_{1}\right\}+P_{b 0}\left[\mathbf{H}_{b}\left(x, x_{b}, \omega\right)\right] \cdot\left\{\mathbf{a}_{3}\right\}, \\
\mathbf{H}_{a}\left(x, x_{a}, \omega\right)=\left[\mathbf{G}_{0}(x, \omega)\left[\mathbf{B}_{L 0}(\omega)\right]^{-1} \mathbf{B}_{L 1}(\omega)-\mathbf{H}_{1}\left(x-x_{a}, \omega\right)\right], \\
\mathbf{H}_{b}\left(x, x_{b}, \omega\right)=\left[\mathbf{G}_{0}(x, \omega)\left[\mathbf{B}_{L 0}(\omega)\right]^{-1} \mathbf{B}_{L 3}(\omega)-\mathbf{H}_{3}\left(x-x_{b}, \omega\right)\right],
\end{array}
$$

with (51)-(52) and matrices $\mathbf{B}_{L 0}(\omega), \mathbf{B}_{L 1}(\omega), \mathbf{B}_{L 3}(\omega)$ provided in Appendix for conventional cases of boundary conditions. The matrices $\mathbf{H}_{a}\left(x, x_{a}, \omega\right), \mathbf{H}_{b}\left(x, x_{b}, \omega\right)$ defined in (50) and (51) can be called transfer matrices for axial and flexural loads respectively. As consequence, the vector functions

$$
\mathbf{h}_{a}=\left[\mathbf{H}_{a}\left(x, x_{a}, \omega\right)\right] \cdot\left\{\mathbf{a}_{1}\right\}=\left\{h_{a 1} \cdot h_{a 2}, h_{a 3}\right\}^{T}, \quad \mathbf{h}_{b}=\left[\mathbf{H}_{b}\left(x, x_{b}, \omega\right)\right] \cdot\left\{\mathbf{a}_{3}\right\}=\left\{h_{b 1} \cdot h_{b 2}, h_{b 3}\right\}^{T},
$$

are called frequency responses of beam to respectively axial and lateral loads. Among the six frequency response functions given in (52) it has to specify the functions

$$
h_{a 1}\left(x, x_{a}, \omega\right), h_{b 3}\left(x, x_{b}, \omega\right), h_{a 3}\left(x, x_{a}, \omega\right), h_{b 1}\left(x, x_{b}, \omega\right) .
$$

The two former functions in (58), $h_{a 1}, h_{b 3}$ are the conventional frequency response functions (FRFs) respectively for axial (longitudinal) and flexural (bending) vibrations which are termed hereby auto-axial and auto-flexural FRFs. The latter functions measure the amplitude of flexural vibration excited by unite axial load $\left(h_{a 3}\right)$ and the amplitude of axial vibration excited by unite lateral load $\left(h_{b 1}\right)$. Therefore, they are called respectively cross axial-flexural and cross flexural-axial FRFs. While the conventional FRFs enable to extract natural frequencies and mode shapes in the modal testing, the cross FRFs provide a useful tool for investigation of coupled vibration in functionally graded Timoshenko beam.

\section{NUMERICAL ILLUSTRATION}

For illustration of the developed above theory in this section modal parameters such as natural frequencies, mode shapes and frequency response functions of simply supported FGM Timoshenko beam are computed in dependence upon the material and geometrical constants. First, to check validity of the governing equations and computational programs, first three natural frequencies of homogeneous beam are computed and tabulated in Tab. 1 where the obtained herein results are compared with exact solution provided in [18] and with those obtained by Su and Banerjee in [6]. It can be seen 
excellent agreement of the compared results, especially in the case of large slenderness ratio $L / h$.

Table 1. Comparison of natural frequencies for homogeneous Timoshenko beam

\begin{tabular}{|c|c|c|c|c|c|c|c|c|c|}
\hline \multirow{2}{*}{$\begin{array}{c}\text { Freq. } \\
\text { No }\end{array}$} & \multicolumn{3}{|c|}{$L / h=10$} & \multicolumn{3}{c|}{$L / h=30$} & \multicolumn{3}{c|}{$L / h=100$} \\
\hline & Present & Ref. [18] & Ref. [6] & Present & Ref. [18] & Ref. [6] & Present & Ref. [18] & Ref. [6] \\
\hline 1 & 2.8023 & 2.8020 & 2.8023 & 2.8437 & 2.8438 & 2.8439 & 2.8486 & 2.8486 & 2.8496 \\
\hline 2 & 10.7087 & 10.6947 & - & 11.3118 & 11.3116 & - & 11.3887 & 11.3887 & - \\
\hline 3 & 15.7080 & 15.7080 & - & 25.2208 & 25.2183 & - & 25.6030 & 25.6030 & - \\
\hline 4 & 22.5613 & 22.4466 & & 44.2849 & 44.2718 & & 45.4628 & 45.4627 & \\
\hline 5 & 37.1427 & 36.7082 & & 47.1239 & 47.1239 & & 70.9284 & 70.9279 & \\
\hline \multicolumn{8}{c|}{} & \multicolumn{8}{c|}{ E $=70 \mathrm{GPa}, \rho=2700 \mathrm{~kg} / \mathrm{m}^{3}, \mu=0.3$} \\
\hline
\end{tabular}

\subsection{Natural frequencies and mode shapes}

For illustration, let's consider the FGM beam with material constants [6]:

$$
E_{b}=210 \mathrm{GPa}, \rho_{b}=7800 \mathrm{~kg} / \mathrm{m}^{3}, E_{t}=390 \mathrm{GPa}, \rho_{b}=3960 \mathrm{~kg} / \mathrm{m}^{3}, n=10, \bar{h}_{0}=0.0653 \text {. }
$$

First, five lowest dimensionless natural frequencies $\lambda=\left(\omega L^{2} / h\right) \sqrt{\rho_{b} / E_{b}}$ of the beam are computed for different length-to-thickness ratios $L / h$ by using the developed above theory with (NA) and without (CA) taking into account of neutral axis dislocation. The results are also compared to those obtained by the dynamic stiffness method in [6] where neutral axis position is assumed to be centroid $\left(h_{0}=0\right)$. Mode shapes related to the computed frequencies are also examined and shown in Figs. 3 that allow identifying axial $\left(A_{k}\right)$ and bending $\left(B_{k}\right)$ modes of vibration. The identified vibration modes corresponding to the computed natural frequencies are shown also in the table under the frequencies (see Tab. 2). Numerical examination shows that mode shapes are dependent rather on the slenderness than material properties of the beam.

Comparison of present results with those given in [6] shows that the proposed above integrated method and the dynamic stiffness method developed by Su and Banerjee [6] are similar in predicting natural frequencies of flexural vibration modes. Nevertheless, they give different results in computing the axial vibration modes which are coupled with the flexural modes in FGM Timoshenko beam. The discrepancy may be explained by the fact that the dynamic stiffness method is often used in combination with Wittrick-Williams algorithm, to the author's knowledge, what has not been verified for the structures with strongly coupled vibration modes such as FGM beam. While, since the proposed in this study method provides an explicit expression for frequency equation, the natural frequencies are computed simply by the secant method. Furthermore, as shown in Fig. 4, taking account of true position of neutral axis, in general, leads to small change in natural frequencies. The deviation of frequencies decreases with raising slenderness ratio and natural frequencies computed based on the neutral axis (NA) and 

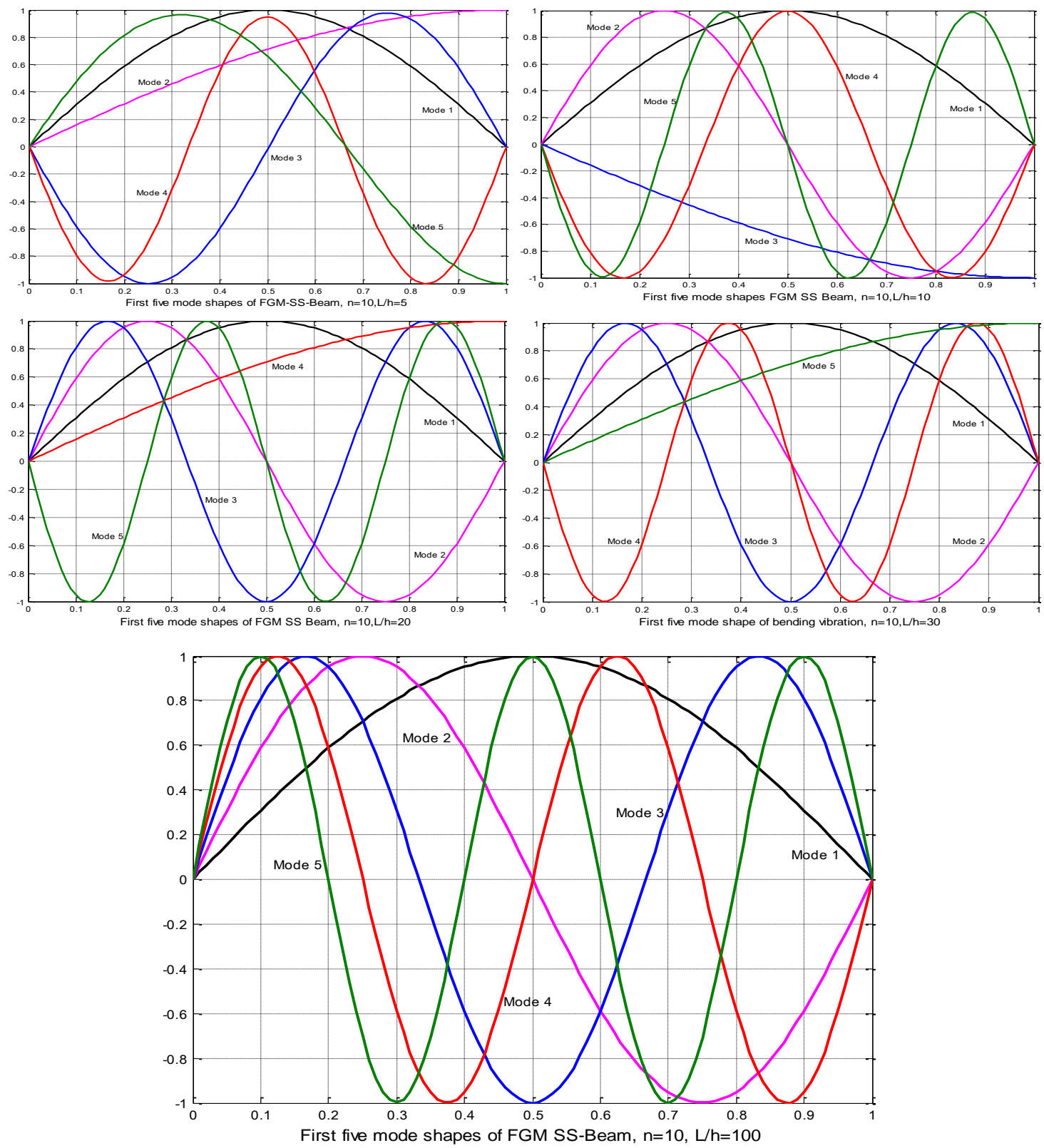

Fig. 3. First five mode shapes of FGM beam with simply supported ends, $L / h=5,10,20,30,100$

centroid axis (CA) theories are almost identical for $L / h=100$. Error in predicting natural frequencies based on the CA-theory reached its maximum for the maximum shift of NA from CA. First (flexural) and third (axial) natural frequencies of the beam with material constants (59) in dependence on the power $n$ are given in Fig. 5 for various ratio $L / h$. It 
Table 2. Comparison of natural frequencies for FGM Timoshenko simply supported beam

\begin{tabular}{|c|c|c|c|c|c|c|}
\hline \multicolumn{2}{|r|}{$L / h$} & $\lambda_{1}$ & $\lambda_{2}$ & $\lambda_{3}$ & $\lambda_{4}$ & $\lambda_{5}$ \\
\hline \multirow{4}{*}{5} & Ref. [6] & 2.9513 & $10.176(10.1162)$ & $16.686(16.6665)$ & $19.331(19.2502)$ & $29.194(29.1011)$ \\
\hline & $\begin{array}{c}\text { Present } \\
\text { (CA) }\end{array}$ & 2.9359 & 8.3233 & 10.1441 & 19.2500 & $24.9647 \quad 29.1027$ \\
\hline & Present & 2.9369 & 8.3405 & 10.1304 & 19.2538 & $24.9626 \quad 29.0944$ \\
\hline & (NA) & $\left(B_{1}\right)$ & $\left(\mathrm{A}_{1}\right)$ & $\left(B_{2}\right)$ & $\left(B_{3}\right)$ & $\left(A_{2}\right)$ \\
\hline \multirow{3}{*}{10} & Ref. [6] & 3.0959 & 11.805 & 24.799 & 33.371 & 40.700 \\
\hline & $\begin{array}{c}\text { Present } \\
(\mathrm{CA})\end{array}$ & 3.0802 & 11.7469 & 16.6775 & 24.6903 & 40.5127 \\
\hline & $\begin{array}{c}\text { Present } \\
\text { (NA) }\end{array}$ & $\begin{array}{c}3.0805 \\
\left(\mathrm{~B}_{1}\right)\end{array}$ & $\begin{array}{c}11.7476 \\
\left(\mathrm{~B}_{2}\right) \\
\end{array}$ & $\begin{array}{c}16.6850 \\
\left(\mathrm{~A}_{1}\right)\end{array}$ & $\begin{array}{c}24.6834 \\
\left(\mathrm{~B}_{3}\right) \\
\end{array}$ & $\begin{array}{c}40.5205 \\
\left(\mathrm{~B}_{4}\right) \\
\end{array}$ \\
\hline \multirow{4}{*}{20} & Ref. [6] & 3.1363 & 12.383 & 27.291 & 47.214 & 66.743 \\
\hline & $\begin{array}{c}\text { Present } \\
\text { (CA) }\end{array}$ & 3.1205 & 12.3206 & 27.1452 & 33.3651 & 46.9994 \\
\hline & Present & 3.1206 & 12.3218 & 27.1584 & 33.3718 & 46.9904 \\
\hline & (NA) & $\left(B_{1}\right)$ & $\left(B_{2}\right)$ & $\left(B_{3}\right)$ & $\left(\mathrm{A}_{1}\right)$ & $\left(\mathrm{B}_{4}\right)$ \\
\hline \multirow{3}{*}{30} & Ref. [6] & 3.1440 & 12.502 & 27.861 & 48.888 & 75.163 \\
\hline & $\begin{array}{c}\text { Present } \\
(\mathrm{CA})\end{array}$ & 3.1282 & 12.4394 & 27.7209 & 48.5505 & $50.8179 \quad 74.8179$ \\
\hline & $\begin{array}{c}\text { Present } \\
\text { (NA) }\end{array}$ & $\begin{array}{c}3.1282 \\
\left(\mathrm{~B}_{1}\right)\end{array}$ & $\begin{array}{c}12.4399 \\
\left(\mathrm{~B}_{2}\right)\end{array}$ & $\begin{array}{c}27.7242 \\
\left(\mathrm{~B}_{3}\right)\end{array}$ & $\begin{array}{c}48.6527 \\
\left(\mathrm{~B}_{4}\right)\end{array}$ & $\begin{array}{cc}50.0582 & 74.8093 \\
\left(\mathrm{~A}_{1}\right) & \left(\mathrm{B}_{5}\right)\end{array}$ \\
\hline \multirow{3}{*}{100} & Ref. [6] & 3.1496 & 12.591 & 28.304 & 50.253 & 78.388 \\
\hline & $\begin{array}{c}\text { Present } \\
\text { (CA) }\end{array}$ & 3.1337 & 12.5285 & 28.1641 & 50.0073 & 78.0119 \\
\hline & $\begin{array}{c}\text { Present } \\
\text { (NA) }\end{array}$ & $\begin{array}{c}3.1338 \\
\left(\mathrm{~B}_{1}\right) \\
\end{array}$ & $\begin{array}{c}12.5285 \\
\left(\mathrm{~B}_{2}\right) \\
\end{array}$ & $\begin{array}{c}28.1668 \\
\left(\mathrm{~B}_{3}\right) \\
\end{array}$ & $\begin{array}{c}50.0095 \\
\left(\mathrm{~B}_{4}\right) \\
\end{array}$ & $\begin{array}{c}78.0140 \\
\left(B_{5}\right) \\
\end{array}$ \\
\hline \multicolumn{7}{|c|}{$\begin{array}{c}\mathrm{A}_{k}-k-\text { th mode of axial vibration; } \mathrm{B}_{k}-k-\text { th mode of bending vibration } \\
\mathrm{CA}-\text { centroid axis; } \mathrm{NA}-\text { neutral axis }\end{array}$} \\
\hline
\end{tabular}

is obviously that natural frequencies are not clearly distinct for $L / h>20$ and they decrease monotonically with growing $n$, but their decreasing is rapidly only for $n<1$ and becomes very slowly for $n>5$. Typical variations of natural frequencies versus neutral axis position $\left(\bar{h}_{0}\right)$, elasticity $\left(R_{1}=E_{t} / E_{b}\right)$ and mass density $\left(R_{2}=\rho_{t} / \rho_{b}\right)$ ratios for various values of power $n$ are depicted in Figs. 6-7 that show obviously monotonic increase (decrease) of natural frequencies with growing neutral axis dislocation and elasticity ratio (mass density ratio). It is observed from Figs. 6-7 that natural frequencies are more sensitive to the ratios for $n<1$ and slowly varying from $n=10$. 


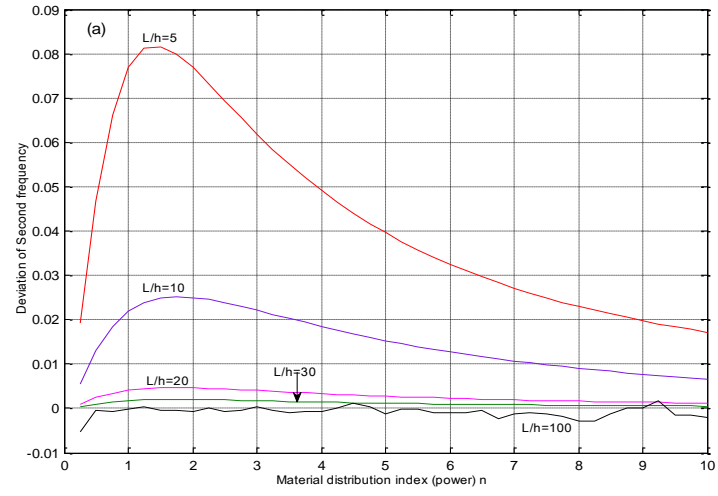

(a) Flexural mode

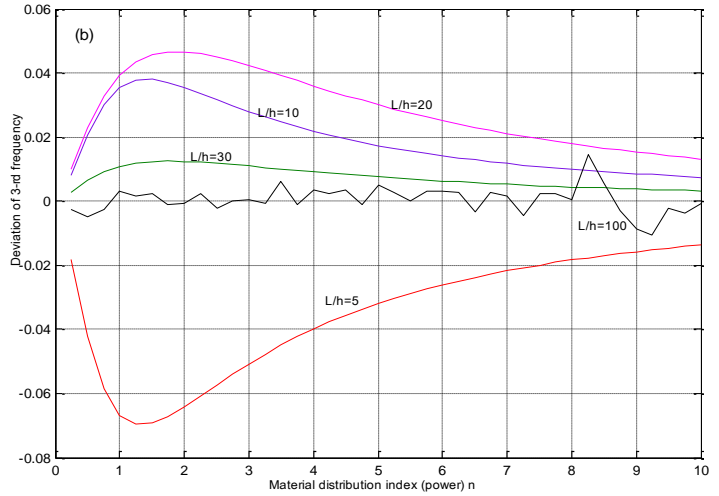

(b) Axial mode

Fig. 4. Deviation (NA-CA) of second (a) and third (b) natural frequencies computed by using neutral axis (NA) and centroid axis (CA) versus power $n$ for various slenderness ratio $L / h$

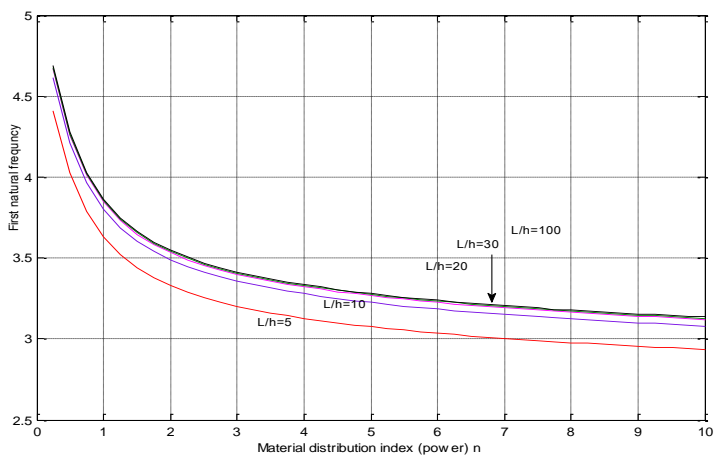

(a)

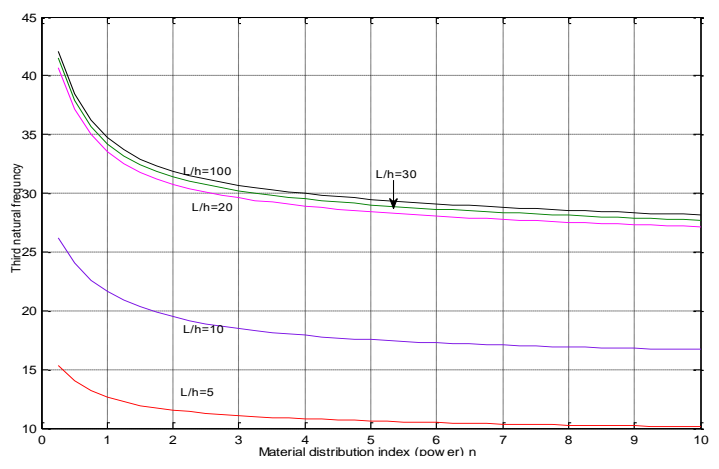

(b)

Fig. 5. Variation of first (a) and third (b) natural frequencies versus power $n$ for various slenderness ratio $L / h$

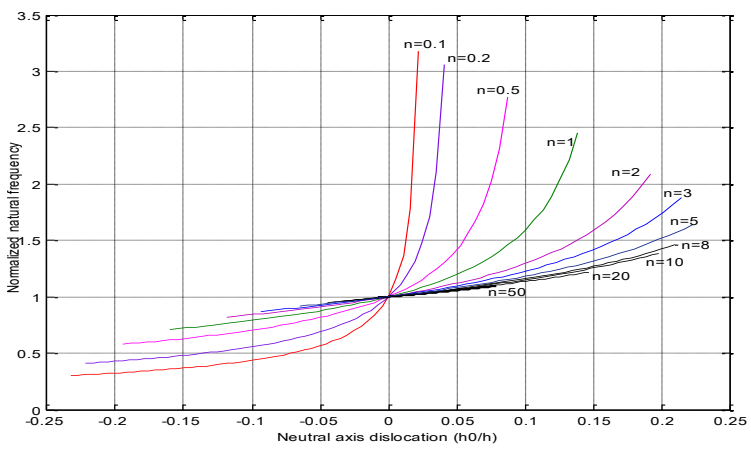

Fig. 6. Normalized natural frequency versus neutral axis dislocation for different power $n$ 


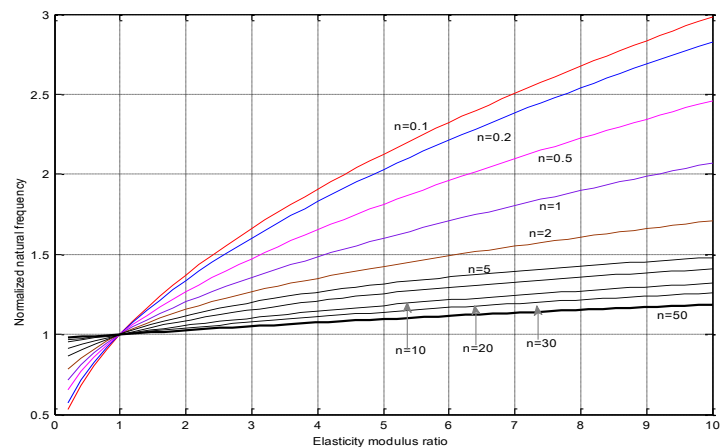

(a)

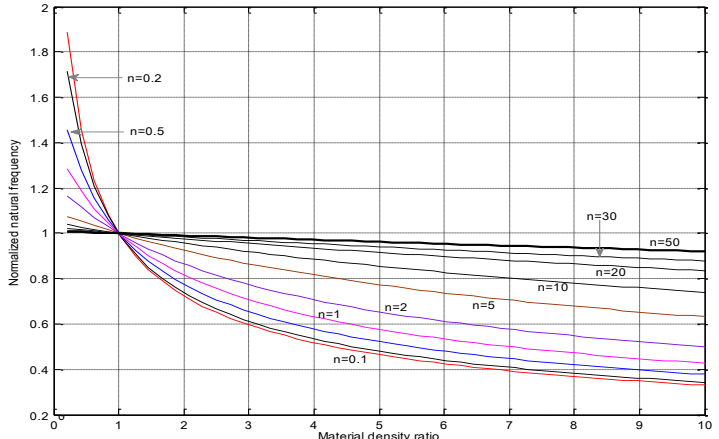

(b)

Fig. 7. Typical variation of natural frequencies versus elasticity (a) and mass density (b) ratios for different material distribution power $n$

\subsection{Frequency response functions}

Frequency response functions (53) for the beam of material constants (59) are computed for various slenderness ratio L/h (Figs. 8-9 and different values of power $n$ (Figs. 1011). The auto FRFs are shown in Figs. 8, 10; the cross FRFs - in Figs. 9, 11 and all of them have been examined independently on the solution of free vibration problem. Obviously, in the plots of auto-axial or auto-flexural FRF (Fig. 8 there appear only natural frequencies of axial or flexural modes. So, both natural frequencies and their modes (axial or flexural) of vibration can be identified directly from measured auto-axial or auto-flexural frequency response functions. Results of extracting natural frequencies and mode shaped from FRFs plotted in Fig. 8 are coincident with those given in Tab. 2 obtained by solving the frequency equation. This enables to make a conclusion that modal parameters such

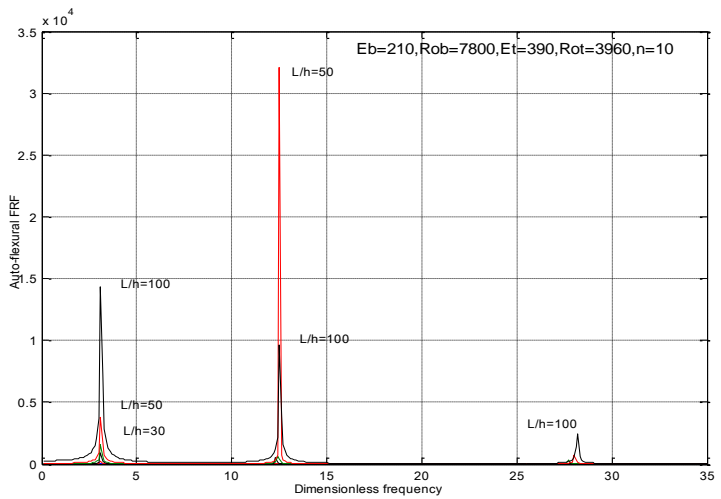

(a)

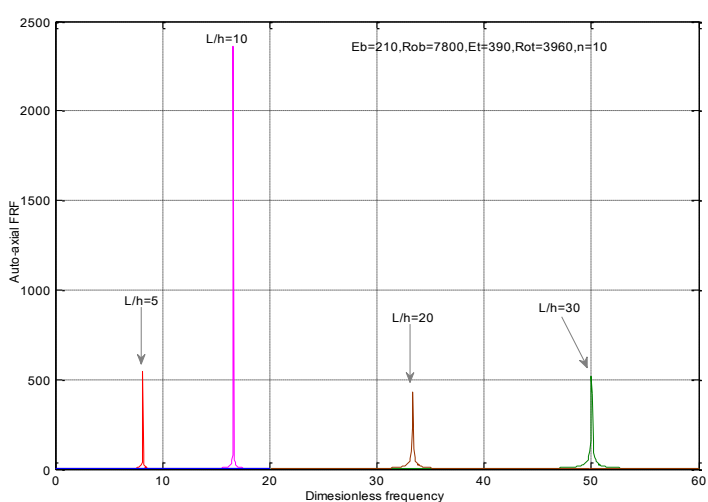

(b)

Fig. 8. Auto-flexural (a) and auto-axial (b) FRFs for various slenderness ratio 
as natural frequencies and mode shapes of FGM Timoshenko beam could be identified by using the conventional modal testing method.

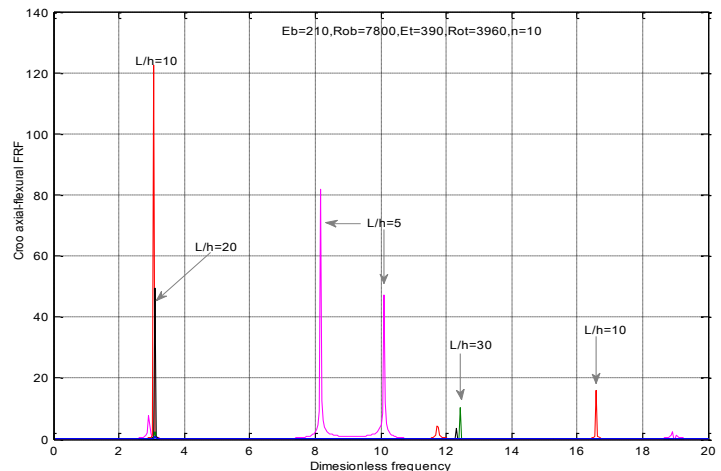

(a)

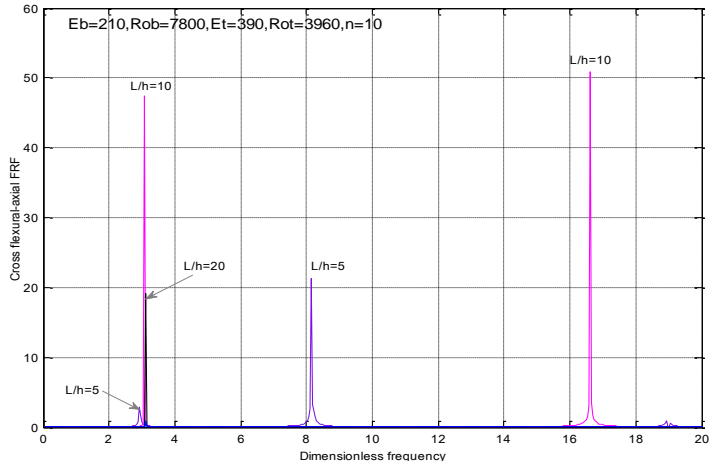

(b)

Fig. 9. Cross axial-flexural (left) and cross flexural-axial (right) FRFs for various slenderness ratio

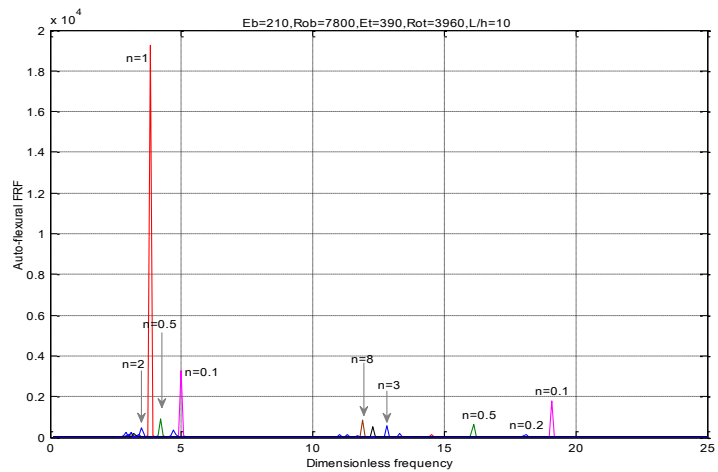

(a)

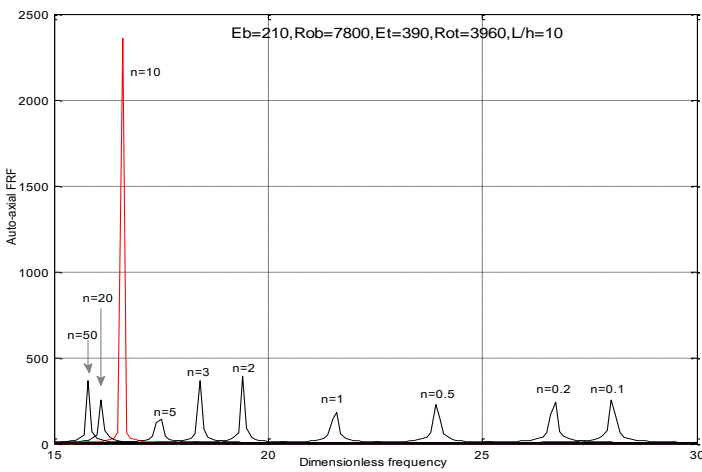

(b)

Fig. 10. Auto frequency response functions for various material distribution index $n$

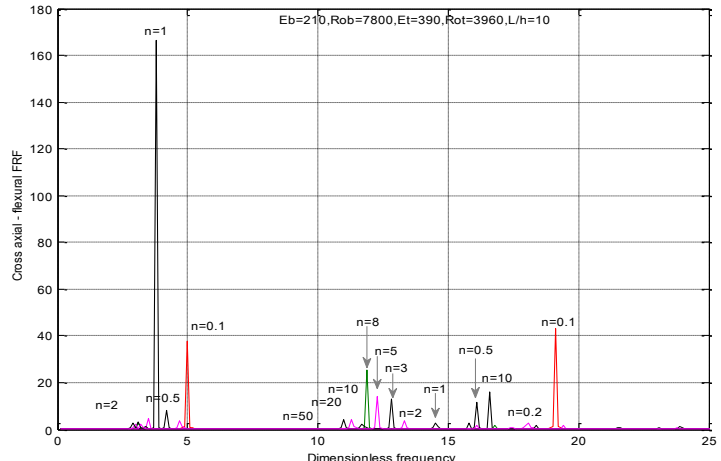

(a)

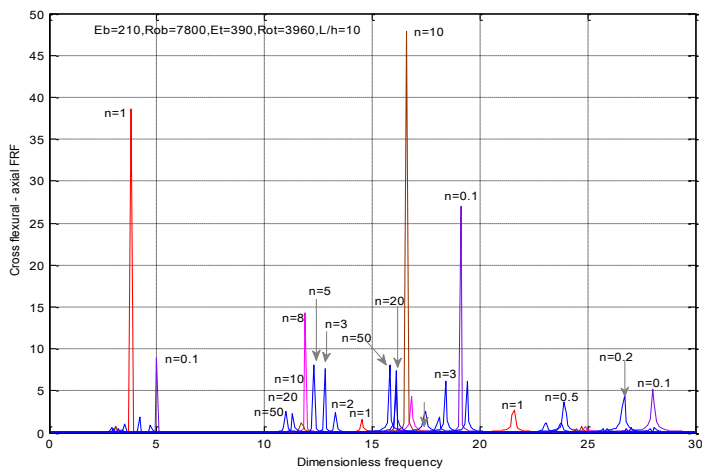

(b)

Fig. 11. Cross frequency response functions for various material distribution index $n$ 
On the other hand, both the axial and flexural vibration modes are observed in the plots of cross frequency response functions (Fig. 9) that demonstrate the actual effect of axial load on the flexural response and lateral load on the axial response, i. e. coupling of the vibration modes. Fig. 10 shows also that axial modes appear clearly on the cross flexural FRF (Fig. 9(a)) only for low slenderness $(L / h=5)$ but the flexural modes are apparently observed on the cross axial FRF plot (Fig. 9(b)) just for $L / h=10$. This confirms the fact that axial modes of vibration are predominated for beam with low slenderness while flexural modes are leading for slender beam.

The auto-flexural and auto-axial FRFs plotted in Fig. 10 for different show monotonic decrease of natural frequencies at all with growing $n$ that is well agreed with the graphs shown in Fig. 5. It can be observed from Fig. 10 that the flexural mode is prevailed for $n=1$ (see Fig. 10(a)) while the axial mode - for $n=10$ (see Fig. 10(b)) what can be seen also in Fig. 11. The frequency response functions computed for various elasticity ratio are presented in Figs. 5 that demonstrate the increase of natural frequencies with growing the elasticity ratio as shown in Fig. 8. Moreover, the graphs of FRFs given in Figs. 12-13 show that axial mode peaks are prevailed for $R_{e}=1 / 6$ and the flexural modes get predominated when $R_{e}=1 / 4$ and 4 .

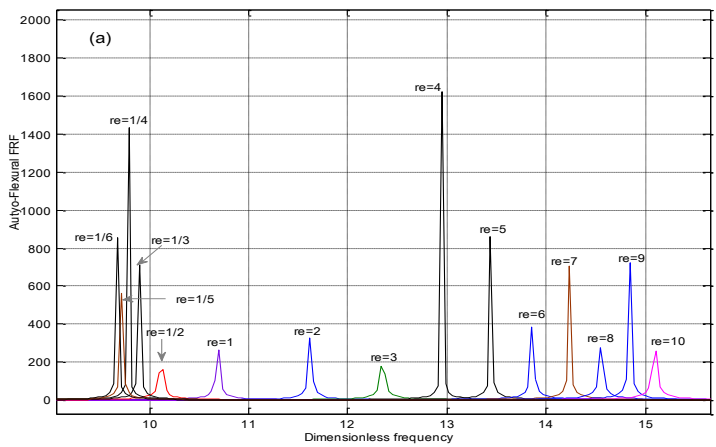

(a)

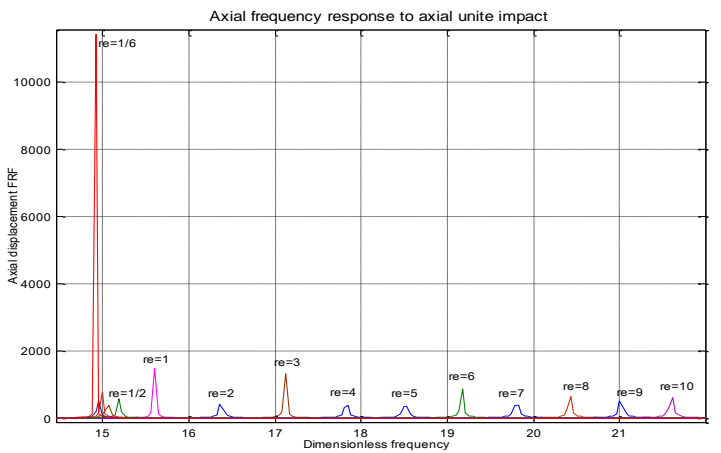

(b)

Fig. 12. Auto frequency response functions for various elasticity modulus ratio

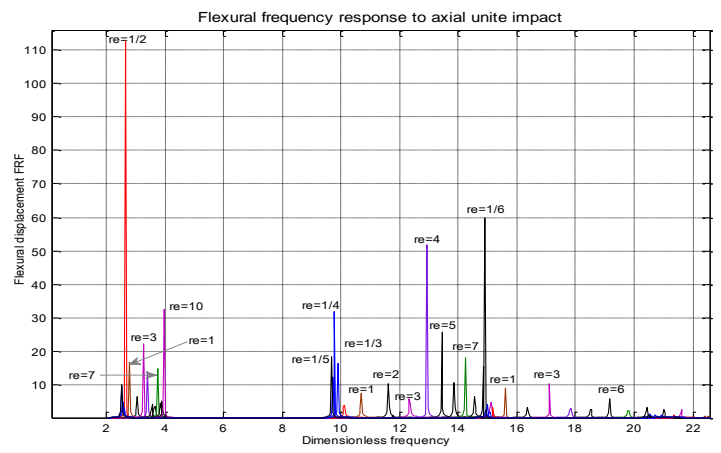

(a)

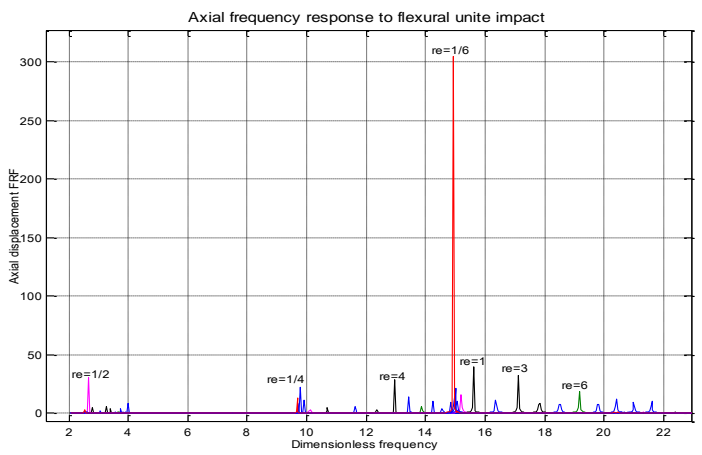

(b)

Fig. 13. Cross frequency response functions for various elasticity modulus ratios 


\section{CONCLUSION}

The main results obtained in present study are as follow:

1. A general vibration theory of functionally graded Timoshenko beam is formulated in the frequency domain with taking into account true position of neutral plane instead of centroid one. In the framework of the proposed theory, there were obtained explicit expressions for frequency equation, mode shapes and various frequency response functions of the beam.

2. Numerical analysis has shown that natural frequencies computed by assuming neutral plane coincident with the centroid one are slightly deviated from those obtained accordingly to the actual neutral plane position. However, the vibration theory based on actual position of neutral plane is straightforward to study coupling of axial and flexural vibration. Namely, there has been obtained a condition for uncoupling of the vibration modes.

3. The established explicit expressions for frequency equation, mode shapes and frequency response functions are essentials for not only modal analysis but also modal testing functionally graded material beams. Moreover, the analytical representations of vibration characteristics provide an efficient tool for identification of FGM beam by vibration-based method.

4. Though numerical analysis was completed only for simply supported beam. The governing equations established in paragraphs 3 and 4 for general boundary conditions are straightforward to use for modal analysis of beam of other end conditions such as cantilevered or clamped ends that have been described in Appendix.

\section{ACKNOWLEDGEMENT}

The authors are thankful to the NAFOSTED of Vietnam for support under Grand of number 107.01-2015.20.

\section{REFERENCES}

[1] S. Suresh and A. Mortensen. Fundamentals of functionally graded materials. ASM International and the Institute of Materials, Cambridge, (1995).

[2] V. Birman and L. W. Byrd. Modeling and analysis of functionally graded materials and structures. Applied Mechanics Reviews, 60, (5), (2007), pp. 195-216. doi:10.1115/1.2777164.

[3] A. Chakraborty, S. Gopalakrishnan, and J. N. Reddy. A new beam finite element for the analysis of functionally graded materials. International Journal of Mechanical Sciences, 45, (3), (2003), pp. 519-539. doi:10.1016/s0020-7403(03)00058-4.

[4] A. E. Alshorbagy, M. A. Eltaher, and F. F. Mahmoud. Free vibration characteristics of a functionally graded beam by finite element method. Applied Mathematical Modelling, 35, (1), (2011), pp. 412-425. doi:10.1016/j.apm.2010.07.006.

[5] D. K. Nguyen. Large displacement response of tapered cantilever beams made of axially functionally graded material. Composites Part B: Engineering, 55, (2013), pp. 298-305. doi:10.1016/j.compositesb.2013.06.024.

[6] H. Su and J. R. Banerjee. Development of dynamic stiffness method for free vibration of functionally graded Timoshenko beams. Computers \& Structures, 147, (2015), pp. 107-116. doi:10.1016/j.compstruc.2014.10.001. 
[7] A. Chakraborty and S. Gopalakrishnan. A spectrally formulated finite element for wave propagation analysis in functionally graded beams. International Journal of Solids and Structures, 40, (10), (2003), pp. 2421-2448. doi:10.1016/s0020-7683(03)00029-5.

[8] M. Aydogdu and V. Taskin. Free vibration analysis of functionally graded beams with simply supported edges. Materials \& Design, 28, (5), (2007), pp. 1651-1656. doi:10.1016/j.matdes.2006.02.007.

[9] X. F. Li. A unified approach for analyzing static and dynamic behaviors of functionally graded Timoshenko and Euler-Bernoulli beams. Journal of Sound and Vibration, 318, (4), (2008), pp. 1210-1229. doi:10.1016/j.jsv.2008.04.056.

[10] K. K. Pradhan and S. Chakraverty. Free vibration of Euler and Timoshenko functionally graded beams by Rayleigh-Ritz method. Composites Part B: Engineering, 51, (2013), pp. 175184. doi:10.1016/j.compositesb.2013.02.027.

[11] S. A. Sina, H. M. Navazi, and H. Haddadpour. An analytical method for free vibration analysis of functionally graded beams. Materials E Design, 30, (3), (2009), pp. 741-747. doi:10.1016/j.matdes.2008.05.015.

[12] D. Wei, Y. Liu, and Z. Xiang. An analytical method for free vibration analysis of functionally graded beams with edge cracks. Journal of Sound and Vibration, 331, (7), (2012), pp. 1686-1700. doi:10.1016/j.jsv.2011.11.020.

[13] K. Aydin. Free vibration of functionally graded beams with arbitrary number of surface cracks. European Journal of Mechanics-A/Solids, 42, (2013), pp. 112-124. doi:10.1016/j.euromechsol.2013.05.002.

[14] M. Şimşek and T. Kocatürk. Free and forced vibration of a functionally graded beam subjected to a concentrated moving harmonic load. Composite Structures, 90, (4), (2009), pp. 465473. doi:10.1016/j.compstruct.2009.04.024.

[15] J. Yang, Y. Chen, Y. Xiang, and X. L. Jia. Free and forced vibration of cracked inhomogeneous beams under an axial force and a moving load. Journal of Sound and Vibration, 312, (1), (2008), pp. 166-181. doi:10.1016/j.jsv.2007.10.034.

[16] M. A. Eltaher, A. E. Alshorbagy, and F. F. Mahmoud. Determination of neutral axis position and its effect on natural frequencies of functionally graded macro/nanobeams. Composite Structures, 99, (2013), pp. 193-201. doi:10.1016/j.compstruct.2012.11.039.

[17] N. T. Khiem and N. N. Huyen. On the neutral axis of FGM beam. In Proceedings of National Conference on Engineering Mechanics. Da Nang, Vietnam, (2015), pp. 164-169.

[18] I. Karnovsky and O. Lebed. Formulas for structural dynamics: tables, graphs and solutions. McGraw-Hill, Inc., (2001). 


\section{APPENDIX}

\section{Boundary condition operators and related matrices}

\section{Simply supported beam}

$$
\begin{aligned}
& \mathbf{B}_{0}=\left[\begin{array}{ccc}
1 & 0 & 0 \\
A_{12} \partial_{x} & -A_{22} \partial_{x} & 0 \\
0 & 0 & 1
\end{array}\right], \quad \mathbf{B}_{L}=\left[\begin{array}{ccc}
A_{11} \partial_{x} & -A_{12} \partial_{x} & 0 \\
A_{12} \partial_{x} & -A_{22} \partial_{x} & 0 \\
0 & 0 & 1
\end{array}\right], \\
& \mathbf{G}_{0}^{s}(x, \omega)=\mathbf{G}_{1}(x, \omega) \mathbf{R}_{1 S}+\mathbf{G}_{2}(x, \omega) \mathbf{R}_{2 S}=\left[g_{j k}(x, \omega) ; j, k=1,2,3\right], \\
& \mathbf{R}_{1 S}=\left[\begin{array}{ccc}
\alpha_{1} & \alpha_{2} & \alpha_{3} \\
k_{1} S_{21} & k_{2} S_{22} & k_{3} S_{23} \\
\beta_{1} & \beta_{2} & \beta_{3}
\end{array}\right]^{-1}, \quad \mathbf{R}_{2 S}=\left[\begin{array}{ccc}
-\alpha_{1} & -\alpha_{2} & -\alpha_{3} \\
k_{1} S_{21} & k_{2} S_{22} & k_{3} S_{23} \\
\beta_{1} & \beta_{2} & \beta_{3}
\end{array}\right]^{-1}, \\
& \mathbf{B}_{L 0}(\omega)=\left[\begin{array}{ccc}
A_{11} g_{11}^{\prime}(L, \omega)-A_{12} g_{21}^{\prime}(L, \omega) & A_{11} g_{12}^{\prime}(L, \omega)-A_{12} g_{22}^{\prime}(L, \omega) & A_{11} g_{13}^{\prime}(L, \omega)-A_{12} g_{23}^{\prime}(L, \omega) \\
A_{12 g_{11}^{\prime}(L, \omega)-A_{22} g_{21}^{\prime}(L, \omega)} & A_{12} g_{12}^{\prime}(L, \omega)-A_{22} g_{22}^{\prime}(L, \omega) & A_{12} g_{13}^{\prime}(L, \omega)-A_{22} g_{23}^{\prime}(L, \omega) \\
g_{31}(L, \omega) & g_{32}(L, \omega) & g_{33}(L, \omega)
\end{array}\right], \\
& \mathbf{B}_{L 1}(\omega)=\left[\begin{array}{ccc}
S_{11} k_{1} \cosh k_{1}\left(L-x_{a}\right) & S_{12} k_{2} \cosh k_{2}\left(L-x_{a}\right) & S_{13} k_{3} \cosh k_{3}\left(L-x_{a}\right) \\
S_{21} k_{1} \cosh k_{1}\left(L-x_{a}\right) & S_{22} k_{2} \cosh k_{2}\left(L-x_{a}\right) & S_{23} k_{3} \cosh k_{3}\left(L-x_{a}\right) \\
\beta_{1} \cosh k_{1}\left(L-x_{a}\right) & \beta_{2} \cosh k_{2}\left(L-x_{a}\right) & \beta_{3} \cosh k_{3}\left(L-x_{a}\right)
\end{array}\right], \\
& S_{1 k}=\alpha_{k} A_{11}-A_{12}, \quad S_{2 k}=\alpha_{k} A_{12}-A_{22}, \quad k=1,2,3 \text {; } \\
& \mathbf{B}_{L 3}(\omega)=\left[\begin{array}{ccc}
S_{11} k_{1} \sinh k_{1}\left(L-x_{b}\right) & S_{12} k_{2} \sinh k_{2}\left(L-x_{b}\right) & S_{13} k_{3} \sinh k_{3}\left(L-x_{b}\right) \\
S_{21} k_{1} \sinh k_{1}\left(L-x_{b}\right) & S_{22} k_{2} \sinh k_{2}\left(L-x_{b}\right) & S_{23} k_{3} \sinh k_{3}\left(L-x_{b}\right) \\
\beta_{1} \sinh k_{1}\left(L-x_{b}\right) & \beta_{2} \sinh k_{2}\left(L-x_{b}\right) & \beta_{3} \sinh k_{3}\left(L-x_{b}\right)
\end{array}\right] .
\end{aligned}
$$

\section{Cantilever beam}

$$
\begin{aligned}
& \mathbf{B}_{0}=\left[\begin{array}{lll}
1 & 0 & 0 \\
0 & 1 & 0 \\
0 & 0 & 1
\end{array}\right], \quad \mathbf{B}_{L}=\left[\begin{array}{ccc}
A_{11} \partial_{x} & -A_{12} \partial_{x} & 0 \\
A_{12} \partial_{x} & -A_{22} \partial_{x} & 0 \\
0 & -A_{33} & A_{33} \partial_{x}
\end{array}\right], \\
& \mathbf{G}_{0}^{C}(x, \omega)=\mathbf{G}_{1}(x, \omega) \mathbf{R}_{1 C}+\mathbf{G}_{2}(x, \omega) \mathbf{R}_{2 C}=\left[g_{j k} ; j, k=1,2,3\right], \\
& \mathbf{R}_{1 C}=\left[\begin{array}{ccc}
\alpha_{1} & \alpha_{2} & \alpha_{3} \\
1 & 1 & 1 \\
\beta_{1} & \beta_{2} & \beta_{3}
\end{array}\right]^{-1}, \quad \mathbf{R}_{1 C}=\left[\begin{array}{ccc}
-\alpha_{1} & -\alpha_{2} & -\alpha_{3} \\
-1 & -1 & -1 \\
\beta_{1} & \beta_{2} & \beta_{3}
\end{array}\right]^{-1} \text {, } \\
& \mathbf{B}_{L 0}=\left[\begin{array}{ccc}
A_{11} g_{11}^{\prime}(L, \omega)-A_{12} g_{21}^{\prime}(L, \omega) & A_{11} g_{12}^{\prime}(L, \omega)-A_{12} g_{22}^{\prime}(L, \omega) & A_{11} g_{13}^{\prime}(L, \omega)-A_{12} g_{23}^{\prime}(L, \omega) \\
A_{12} g_{11}^{\prime}(L, \omega)-A_{22} g_{21}^{\prime}(L, \omega) & A_{12} g_{12}^{\prime}(L, \omega)-A_{22} g_{22}^{\prime}(L, \omega) & A_{12} g_{13}^{\prime}(L, \omega)-A_{22} g_{22}^{\prime}(L, \omega) \\
A_{33}\left[g_{21}(L, \omega)-g_{31}^{\prime}(L, \omega)\right] & A_{33}\left[g_{22}(L, \omega)-g_{32}^{\prime}(L, \omega)\right] & A_{33}\left[g_{23}(L, \omega)-g_{33}^{\prime}(L, \omega)\right]
\end{array}\right], \\
& \mathbf{B}_{L 1}=\left[\begin{array}{ccc}
S_{11} k_{1} \cosh k_{1} L_{a} & S_{12} k_{2} \cosh k_{2} L_{a} & S_{13} k_{3} \cosh k_{3} L_{a} \\
S_{21} k_{1} \cosh k_{1} L_{a} & S_{22} k_{2} \cosh k_{2} L_{a} & S_{23} k_{3} \cosh k_{3} L_{a} \\
S_{31} \sinh k_{1} L_{a} & S_{32} \sinh k_{2} L_{a} & S_{33} \sinh k_{3} L_{a}
\end{array}\right], \quad L_{a}=L-x_{a}, \\
& \mathbf{B}_{L 3}=\left[\begin{array}{ccc}
S_{11} k_{1} \sinh k_{1} L_{b} & S_{12} k_{2} \sinh k_{2} L_{b} & S_{13} k_{3} \sinh k_{3} L_{b} \\
S_{21} k_{1} \sinh k_{1} L_{b} & S_{22} k_{2} \sinh k_{2} L_{b} & S_{23} k_{3} \sinh k_{3} L_{b} \\
S_{31} \cosh k_{1} L_{b} & S_{32} \cosh k_{2} L_{b} & S_{33} \cosh k_{3} L_{b}
\end{array}\right], \\
& S_{3 j}=A_{33}\left(\beta_{j} k_{j}-1\right), \quad j=1,2,3 ; \quad L_{b}=L-x_{b} \text {. }
\end{aligned}
$$




\section{Clamped end beam}

$$
\begin{aligned}
& \mathbf{B}_{0}=\mathbf{B}_{L}=\mathbf{I}_{3}, \\
& \mathbf{G}_{0}^{C}(x, \omega)=\mathbf{G}_{1}(x, \omega) \mathbf{R}_{1 C}+\mathbf{G}_{2}(x, \omega) \mathbf{R}_{2 C}=\left[g_{j k} ; j, k=1,2,3\right], \\
& \mathbf{R}_{1 C}=\left[\begin{array}{ccc}
\alpha_{1} & \alpha_{2} & \alpha_{3} \\
1 & 1 & 1 \\
\beta_{1} & \beta_{2} & \beta_{3}
\end{array}\right]^{-1}, \quad \mathbf{R}_{1 C}=\left[\begin{array}{ccc}
-\alpha_{1} & -\alpha_{2} & -\alpha_{3} \\
-1 & -1 & -1 \\
\beta_{1} & \beta_{2} & \beta_{3}
\end{array}\right], \\
& \mathbf{B}_{L 0}(\omega)=\mathbf{G}_{0}^{c}(L, \omega), \quad \mathbf{B}_{L 1}(\omega)=\mathbf{H}_{1}\left(L-x_{a}, \omega\right), \quad \mathbf{B}_{L 3}(\omega)=\mathbf{H}_{3}\left(L-x_{b}, \omega\right) .
\end{aligned}
$$

